\title{
Chapter 5
}

\section{Cultural Differences in}

\section{Understanding Social Capital - Wasta and Social Capital}

Omar Shaheen

University of Lodz, Poland

PhD candidate

https://doi.org/10.18778/8220-533-6.06

\section{Abstract}

Wasta (in the Arabic literature wasta) means "intercession" or "mediation". This concept covers a wide range of social activities. In the West it is known as clientelism, due to the existence of an informal relationship between the client (requestor of Wasta-demanding interest) and the possessor. The purpose of this paper is to analyze Wasta in an Arabic country through the three dimensions of the social capital (structural, cognitive, relational). To achieve this aim a theoretical research method was used to analyze Wasta. As a social mechanism in an Arabic country, Wasta can be considered an example of social capital, due to the fact that it contains the structural, cognitive and relational dimensions of the social capital mentioned in the literature.

Keywords: social capital, Wasta, client, possessor, structural dimension, cognitive dimension, relational dimension

\section{Introduction}

The concept of social capital has been at the forefront of social sciences in the past century. Researchers of political sciences (Putnam 1995, 2000), sociology (Granovetter 1973, Coleman 1998, Portes 1998), ethics (e.g. Ayios 2014), human resources management, business (Woolcock 1998, Fernandez 2000) and economy, have used social capital as a core concept in analyzing how an actor's social network effects (their) access to different resources and ability to achieve aspirations and goals (Burt 2005). The main assumption in the literature on social capital is that social 
networks contain value that can be acquired by the individuals of such a network (Putnam 2000). This value is attained by providing essential resources and assets to individuals who tend to improve the productivity of both groups and individuals in similar ways to other forms of capital such as human and physical capital (Putnam 2000). The added value of a social network is a point of agreement connecting social capital researchers.

Wasta relates to situations when relationships between individuals are used to achieve goals and interests through linking people who share mutual favors, benefits, background, interests and/or characteristics. In the Arab Middle East countries the practice of using a social network to get access to resources or to achieve goals is known as Wasta, sometimes defined as favoritism based on family and tribal affiliation (Cunningham and Sarayrah 1993). Wasta is argued to be a common practice that has a substantial effect on the social, business and political interactions in the Arab Middle East (Berger et al. 2014). Today Wasta is practiced for different reasons, including political aims (such as to win parliamentary elections) (Branine and Analoui 2007), social (arranging meetings and solving social issues), economic (securing promotion, getting a job), or cutting through the red tape in government interactions (Loewe et al. 2007).

\section{Social Capital}

In the past, the evolution of human capital attracted attention to issues of how an individual's background, skills and education are required to be effective and productive in the highly competitive labor market. Sociologists such as James Coleman, Mark Granovetter and Ron Burt argue that analyzing and explaining variations in individual accomplishments and social position only through personal characteristics is not enough. This school of thought claims that "even in recent institutional economics we can observe a failure to recognize and identify the value of networks of relations and concrete individual (personal) relationships and ... in establishing expectations, in generating trust, and in creating and enforcing norms" (Coleman 1988).

Addressing these issues in the classic economic theory and studies, the concept of social capital, the "web of social relationships that effect individual attitude and behavior and by that affects economic success" was reviewed and developed (Pennar 1997). The concept of social capital has become noticeably popular in a wide range of social science studies. A growing number of political scientists, economists, and sociologists are using it to find answers to a range of questions and issues in their own disciplines (Adler and Kwon 2002).

In the recent years, there has been an increase in the use of the social capital theory, even though it has been around for quite some time and is highly popular in a wide range of social studies. Thanks to Putman, Coleman and Bourdieu's work, the 
social capital theory has become a widely known and accepted concept in different social disciplines (Hoi, Wu and Zhang 2018). It is deeply rooted in theorists including Alexis de Tocqueville, James Madison amongst others in American political studies (Garson 1978). In the literature it is hard to find one single social capital theory; in fact, there are a few contradicting theories which try to establish a clear understating of what social capital actually is (Jackman and Miller 1998). In spite of the great interest among researchers it is difficult to find a clear explanation of this concept (Frukuyama 1995). Putman introduces social capital as "the connections among individuals - social networks and the norms of reciprocity and trustworthiness that arise from them" (Putnam 2000).

Social capital is a mechanism which provides individuals with an access to resources embedded in different social relationships empowering individuals to facilitate action via organizing these hidden resources (Luoma-Aho 2018). It has provided fundamental formative principles for a number of studies including education and schooling, economic development, and community life (Adler and Kwon 2002). Putnam's explanation of social capital is that it incorporates elements such as network structures, norms, trust, which boost cooperation between individuals in a community, offering mutual benefits. Coleman argues that appropriability validates a conceptual strategy by enveloping social exchange, trust, resources and support, cultural ${ }^{1}$.

The structural dimension concerns individuals building networks with others, since it is fundamental in the establishing of social capital (Hoi, Wu and Zhang 2018). The structural dimension of the social capital includes relationships connecting individuals (actors) within networks (Adler and Kwon 2002). Such network connections amongst individuals are established as an outcome of interpersonal relationships via informal social meetings (Inkpen and Tsang 2005). The term "network" illustrates the collaboration process between actors within a specific organization and, therefore, is used differently than in public administration research. Research has revealed how the network configuration, the networks ties and the high levels of social interactions between actors enhance and foster the process of flexibility and knowledge exchange within an organization (Granovetter 1973). Personal interaction between the individuals within a network can have a positive effect called "timing effects", due to the fact that network enhances both the access to information and knowledge, and also causes that individuals are informed quickly and directly.

The cognitive dimensions of the social capital relate to the shared understanding and the meaning between the network actors and include two main facets that are shared in the culture and goals (Nahapiet and Ghoshal 1998). Shared culture specifies the level to which norms of behavior manage relationships, when shared goals affect the degree to which network actors allocate approach to the achievement, mutual understanding and outcomes (Gulati, Nohria and Zaheer 2000). The process of sharing mutual goals between actors is carried out either through codes, language

1 R. Dore, British Journal of Sociology 34(4), pp. 459-482. 
and narratives, or sometimes combination of both. Language is a fundamental factor/tool for exchange in social interaction and relation among individuals. Codes enhance the process of building a mutual language that supports the interaction and communication process, and the capacity for individuals to create a mutual understanding (Hoi and Zhang 2018). Therefore, shared language and codes might create a mutual conceptual apparatus for evaluating the benefits of individual social exchange (Nahapiet and Ghoshal 1998). Also, shared narratives such as metaphors, stories and myths create powerful ways for building, protecting, and exchanging rich sets of meanings (Nahapiet and Ghoshal 1998).

The relational is the concept used to illustrate the type of personal relationships individuals build with each other through mutual interaction (Granovetter 1992, Hollenbeck and Jamieson 2015). The relational dimension of social capital describes the individuals interaction including friendship and respect effecting their behavior of achieving social motives such as approval, prestige, and sociability (Hollenbeck and Jamieson 2015). It points out matters related to values and shared norms, expectations, trust, obligation and identification that are essential in building the social capital among individuals. Francis Fukuyama in his book entitled Trust, argues that trust is the expectation that takes place within a community of cooperative, regular behavior and honesty, based on mutual norms on the part of the other actors of that community. (...) Social capital is the potential that appears from the prevalence of trust between individuals in the community or certain part of it (Fukuyama 2000). Trust can be embodied both in smallest social groups, such as families, as well as in the largest of all groups: the society. The social capital varies from other forms of human capital because it is commonly built and transferred through cultural mechanisms like religion, historical habit or tradition (Fukuyama 2000). For example, two individuals may occupy equivalent positions in the same network configurations, but if their emotional and personal attachments to actors of other networks vary, their actions are also likely to vary in crucial respects (Allameh 2018).

\section{Wasta through the eyes of social capital construct}

Wasta means "intercession" or "mediation" (in the Arabic language literature) (Abdalla, Maghrabi and Raggad 1998). The Wasta concept is related to favoritism: tribalism based on tribal and family relations (Caputo 2018). Wasta can be also referred to as maiarifa (who you know) or as piston (pulling strings) (Yahiaoui and Zoubir 2006). Wasta relates to situations when relationships between individuals are used to achieve goals and interests through linking individuals who share mutual favors, benefits, background, interests and/or characteristics. Similarly, the "pulling string" term is common in the UK and it regards gaining interest through networks connections, which may be either short-term relationships, such as acquaintances, or long terms connections, such as family (Alwerthan, Swanson and Rogge 2018). 
It lways involves a middle individual who possesses, and at the same time is able to share a particular benefit or interest for a certain party. The Wasta concept consists of three main stages: 1) the client (requestor of Wasta-demanding interest), i.e. the one who makes claims, 2) the possessors of Wasta, 3) the resources (granted interest) (Mohamed and Hamdy 2008). From this context Wasta has the structural dimension of social capital where Wasta includes relationships, connecting individuals (client-possessors) within the networks, network's ties - an essential aspect of Wasta creating opportunities for transactions of interests (Alwerthan, Swanson and Rogge 2018).

The structural dimension of Wasta as a network is seen as a mechanism that helps individuals get access to resources in the possession of other individuals in the network. From the structural aspect, Wasta aspect refers to a set of practices which an individual is expected to use to extend interests to family, friends and other individuals from their tribe. Wasta includes nepotism (favours to own family), cronyism (favours to close friends) and favoritism (individuals in own social network) (Abdalla, Maghrabi and Raggad 1998). The concept covers a wide range of social activities and is therefore difficult to translate into Western conceptual categories. The closest is clientelism, because it assumes the existence of an informal relationship between the patron and the client, and it relates to both economic and political sphere. Clientelism, however, relates only to an intercessory type of Wasta. Wasta is a broader concept than nepotism. Favors within it usually concern one's own group - a tribe, clan, family, religious group. However, this relationship can also include unrelated people - for example, a politician and a potential voter who offers his vote in exchange for benefits (Weir, Sultan and Van De Bunt 2016).

The example cited above indicates the corruption-generating nature of Wasta, but it is not synonymous with corruption (Weir, Sultan and Van De Bunt 2016). If the Wasta relationship does not occur at the expense of a third party (state, nation, other person), it is not corruption. For this reason, a distinction is made between "good" and "bad" Wasta (Loewe 2007: 55) - a Wasta that benefits and Wasta that negatively impacts the social system (benefiting the individual). A good Wasta is, for example, particular dedication of an employee to the company and to the supervisor because of their relationship; bad - if it is a state-owned company, and the hiring decision was determined by family ties rather than by professional qualifications. A good Wasta can be a mediation between two individuals to resolve a conflict in a way that is beneficial and fair to both parties; bad - if someone uses individual connections in a conflict, and the mediator pushes a solution which is only beneficial for one party.

Analyzing Wasta through the Cognitive dimensions of the social capital relates to shared understanding and meaning between Wasta exchange: the actor providing the favour and the individual (the client - the beneficiary) looking for the favour and includes the shared culture and the goals between those two parties (Alwerthan, Swanson and Rogge 2018). Shared culture and goals between the client and the possessors of Wasta, when the client believes that the received favor is their right. Norms in a Wasta relationship create and manage behaviors where there is a mindset 
of the client and the possessor, and is based on that shared cultural relationships are built and managed (Alwerthan, Swanson and Rogge 2018). The shared language in Wasta can be noticed since Wasta refers to a situation where relationships and connections between individuals are used to achieve goals through connecting people with the same mindset and shared benefits, favors, background, interests (Caputo 2018). Wasta is a social context which generates the language and codes for the individuals that participate in this social mechanism. Wasta is a process in which individuals achieve goals through using the link the key person, using the client and the possessor language, codes and shared culture. This happens when the individuals of power intervenes on behalf of the client to help them resolve a personal issue or to create an opportunity or to deliver a favour.

In the organizational context, Wasta means to get a promotion, employment or other preferential treatment from members or relatives of the extended tribe. Wasta in the Arabic world may seem similar to nepotism in the Western world, however, it is more all-encompassing and far-reaching. The client and the possessor share language and codes that the Wasta mechanism provides to create a mutual conceptual apparatus for evaluating the favours of actors' social exchange, using the Wasta mechanism. The shared narratives and stories both between the client and the possessor create a rich set of meanings illustrated in the inequality of power of the beneficiary aspect of Wasta mechanism. Therefore, Wasta as a social mechanism contains the cognitive dimension of social capital represented with the shared understanding and meaning. The Wasta practice in the Arabic world provides the client and possessor through a well-established set of mutual understandings and meanings which build the shared culture and goals between them. This mutual understanding between the client and the possessor illustrated in the context of the benefit can be mutual or a returned favor.

Shared culture specifies the level to which norms of behavior manage relationships when shared goals affect the degree to which network actors allocate approach to the achievement, mutual understanding and outcomes (Gulati, Nohria and Zaheer 2000). The process of sharing mutual goals between actors carried out either through codes, language and narratives, or sometimes a combination of both. Language is a fundamental process for exchange in social interactions and relations among individuals. Codes enhance the process of building a mutual language that supports the interaction and communication process and the capacity for individuals to create a mutual understanding. Therefore, shared language and codes might create a mutual conceptual apparatus for evaluating the benefits of individuals social exchange (Nahapiet and Ghoshal 1998). Also, shared narratives such as metaphors, stories and myths create the powerful means in community for building, protecting, and exchanging rich sets of meanings between the client and the possessor (Weir, Sultan and Van De Bunt 2016).

The relational aspect of Wasta can be seen through the personal relationships the client and the possessor build through interactions. Wasta has a place between the client and the possessor when their relationship is based on friendship and mutual 
respect, which effect the behavior of the possessor to achieve social motives for the client such as creating an opportunity or supporting them to get a favour (Alwerthan, Swanson and Rogge 2016). Wasta assumes the expectations that the client has towards the possessor that they will deliver or solve his problem. Traditionally, Wasta was used as a mechanism of solving disputes between families through respected and well-known individual (the head of the family). This individual's job was to negotiate and reconcile any problems between the conflicted groups. However, today Wasta relates to the trust that the client has towards the possessor, in order to provide a personal benefit. Wasta emerged in the Arabic world because of the inequality in the financial system. Individuals believed that using Wasta can reduce the transaction cost needed to possess a resource (Brandstaetter, Bamber and Weir 2016). Wasta takes the form of an administrative service that handles procedures and documents (Hooker 2018). In this context Wasta is a tool that contributes to personal trust between the client and the possessor, and enhances the chance of having a successful cooperation. As result, individuals may seek out to Wasta as a resource, as they trust that it can influence the decision making in a way that will benefit them in the short and long term (Alreshoodi 2018).

\section{Conclusion}

Many individuals in the Arab societies argue that Wasta is benevolent. Wasta is considered as poor people's weapon used to achieve goals or to receive equal treatment when they are not able to build connections with authorities efficiently. As a result, the Wasta mechanism is still in practice, due to the fact that this mechanism is embedded in the society's social culture, because of the corrupted political and weak economic condition (Adi 2014). Individuals generally started giving and using Wasta because it is viewed as an obligation and an expectation, a source of psychological satisfaction from using the possessor power, and a tool for creating and maintaining one's own network of connection for the purpose of securing present and future interests. In the business context Arab managers of SMEs use Wasta to secure markets contracts, create opportunities and increase their chance of success.

Considering the characteristics of the relationship between the client and possessor Wasta is an example of a social construct (social capital) because it fulfills all its features (Sztompka 2020). It assumes the existence of a multitude of interactions that are multi-thematic. They can be specialized (e.g. obtaining a driving license by a client) or can relate to various spheres of life (e.g. activities aimed at raising the standard of living of the client - from facilitating access to basic goods or services to providing work). Wasta is a lasting relationship, which is known for its specific characteristics and the expectations of the client and the possessor towards each other. Its feature is also the normative regulation; it is regulated by certain patterns (Roniger 2004). They are not formalized, but they set the framework for mutual 
expectations and rights. The client has the right to expect his patron (possessor) to find him employment in the office - if they have agreed to do so. In turn, the possessor has the right to expect the client's loyalty. Finally, the relationships arising from Wasta are imposed on the partners (client-possessor) of the relationship because of their social positions (Roniger 2004). For individuals the access that Wasta gives them is its positive social capital and for individuals whom are excluded or do not have an access do Wasta it is considered as negative social capital. Wasta has become a key concept, explaining the failure of Arab countries in the economic and political reforms. However, the Wasta concept definitely goes beyond the negative practice that is associated with it - nepotism, cronyism and corruption. The practice of Wasta is not limited to the Arab culture, although the Wasta terminology changes across countries and regions; Gunaxi in China, pulling strings in the UK, Blat in Russia. Wasta also means mediation, lobbying and social solidarity (Feghali 2014). Finally, in both good and bad forms of Wasta, as well as in a whole range and variety, practices referred to as Wasta have existed in other cultures.

\section{References}

Abdalla, H., Maghrabi, A., Raggad, B. (1998), Assessing the Perceptions of Human Resource Managers toward Nepotism. A Cross-Cultural Study. "International Journal of Manpower", vol. 19, No. 8, pp. 554-557.

Adler, P. S., Kwon, S. W. (2002), Social capital: Prospects for a new concept. "Academy of Management Review", vol. 27, No. 1, pp. 17.

Allameh, S. M. (2018), Antecedents and consequences of intellectual capital: The role of social capital, knowledge sharing and innovation. "Journal of Intellectual Capital”, vol. 19, No. 5, pp. 858-874.

Alreshoodi, S. A. (2018), Public Service Motivation, Wasta and Employee Outcomes in the Saudi Public Sector. "Arabian J Bus Manag Review", vol. 8, No. 354, pp. 2-4.

Alwerthan, T. A., Swanson, D. P., Rogge, R. D. (2018), It's better to give than to receive: Psychological need satisfaction mediating links between wasta (favouritism) and individuals' psychological distress. "International Journal of Psychology", vol. 53, No. 51, pp. 11-20.

Berger, R., Silbiger, A., Herstein, R., Barnes, B. (2014), Analyzing business-to-business relationships in an Arab context. "Journal of World Business", vol. 53, No. S1, pp. 1-11.

Brandstaetter, T., Bamber, D., Weir, D. (2016), Wasta: Triadic Trust in Jordanian Business. In The political economy of Wasta: use and abuse of social capital networking. Springer, Cham. pp. 5-6.

Branine, M., Analoui, F. (2006), Human resource management in Jordan. In: P. S. Budhwar, K. Mellahi, Managing Human Resources in the Middle East. Abingdon: Routledge, pp. $145-160$.

Burt, R. S. (2005), Brokerage and Closure: An Introduction to Social Capital, Oxford: Oxford University Press.

Coleman, J. S. (1994), Foundations of social theory. Harvard University Press.

Cunningham, R. B. (1993), Sarayrah, Y. K., Wasta: The Hidden Force in Middle Eastern Society. Praegar: Westport, Connecticut, pp. 1. 
Dore, R. (1983), Goodwill and the spirit of market capitalism. "British Journal of Sociology", vol. 34, No. 4, pp. 459-482.

Feghali, R. (2014), Wasta: connections or corruption in the Arab World? "Global investigator", vol. 28, pp. 1-3.

Fernandez, R. M., Castilla, E. J., Moore, P. (2000), Social Capital at Work: Networks and Employment at a Phone Center. "American journal of sociology", vol. 105, No. 5, pp. $1288-1356$.

Fukuyama, F. (2000), Social Capital and Civil Society. "IMF Working Paper”, vol. 1, pp. 1-19, Available at SSRN: https://ssrn.com/abstract=879582

Fukuyama, F. (1995), Trust: The Social Virtues and The Creation of Prosperity, Free Press Paperbacks.

Garson, G. D. (1978), Group theories of politics. Beverly Hills, CA: Sage.

Granovetter, M. S. (1973), The strength of weak ties. "American journal of sociology”, vol. 78, No. 6, pp. 1360-1380.

Granovetter, M. (1992), Problems of explanation in economic sociology. In N. Nohria, R. Eccles (eds), Networks and Organizations: Structure, Form and Action. Harvard Business School Press, Boston, MA, pp. 25-56.

Granovetter, M. (1995), The economic sociology of firms and entrepreneurs. In A. Portes (ed.), The Economic Sociology of Immigration, New York: Russell Sage Foundation, pp. 128-165.

Gulati, R., Nohria, N., Zaheer. A. (2000), Strategic networks. "Strategic management journal", vol. 21, No. 3, pp. 203-215.

Hoi, C. K., Wu, Q., Zhang, H. (2018), Community social capital and corporate social responsibility. "Journal of Business Ethics", vol. 152, No. 3, pp. 647-665.

Hollenbeck, J. R., Jamieson, B. B. (2015), Human capital, social capital, and social network analysis: Implications for strategic human resource management. "Academy of Management Perspectives", vol. 29, No. 3, pp. 370-385.

Hooker, J., Corruption from a cross-cultural perspective. (Working Paper). Carnegie-Mellon University. Retrieved March 11, 2018, pp. 14-18.

Inkpen, C., Tsang, E. W. (2005), Social Capital, Networks, and Knowledge Transfer. "Academy of management review", vol. 30, No. 1, pp. 146-165.

Jackman, R. W., Miller, R. A. (1998), Social capital and politics. "Annual Review of Political Science", vol. 1, No. 1, pp. 47-73.

Loewe, M., Blume, J., Schönleber, V., Seibert, S., Speer, J., Voss, C. (2007), The Impact of Favouritism on the Business Climate: A Study on Wata in Jordan. "Studies", vol. 30, No. 30, pp. 1-211.

Mohamed, A. A., Hamdy, H. (2008), The Stigma of Wasta. The Effect of Wasta on Perceived Competence and Morality. "Working Paper", No. 5, German University in Cairo, pp. 1-3.

Paniccia, I. (1998), One, a hundred, thousands of industrial districts. Organizational variety in local networks of small and medium-sized enterprises. "Organization Studies", vol. 19, No. 4, pp. 667-699.

Pennar, K., Mueller, T. (1997), The ties that lead to prosperity. "Business Week", vol. 15, No. 1, pp. 153-154.

Putnam, R. (2000), Bowling alone. New York: Simon and Schuster, pp. 18-19.

Ramady, M. (2015), The Political Economy of Wasta: Use and Abuse of Social Capital Networking. Springer, pp. 23-27.

Roniger, L. (2004), Political Clientelism, Democracy and Market Economy. "Comparative Politics", vol. 36, No. 3, pp. 353-355. 
Sztompka, P. (2002), Socjologia Analiza społeczeństwa. Kraków: Znak, pp. 89-90.

Yahiaoui, D., Zoubir, Y.H. (2006), Human resource management in Tunisia, Routledge.

\section{Key Terms and Definitions}

Social capital - refers to the social capital as the connections among individuals - social networks and the norms of reciprocity and trustworthiness that arise from them. Social capital is what provides access to resources embedded in social relationships enabling people to facilitate action via mobilising these hidden assets.

Wasta - relates to situations when relationships between individuals are used to achieve goals and interests through linking individuals who share mutual favors, benefits, background, interests and/or characteristics.

Structural dimension - this dimension of social capital includes relationships connecting individuals (actors) within the networks, where the network's ties - an essential aspect of social capital are connected to the elements building opportunities for social capital transactions

Cognitive dimension - this dimension of the social capital relates to shared understanding and meaning between network actors and include two main facets that are shared culture and goals.

Relational dimension - is the concept used to illustrate the type of personal relationships individuals build with each other through mutual interaction.

\section{Autobiographical Note}

Omar H. A. Shaheen PhD student in the Faculty of Management University of Lodz, Poland. His research interests are social capital and community of practice. On a daily basis employed in multinational outsourcing company.

ORCID ID https://orcid.org/0000-0001-8021-1833 